\title{
ANALISIS PENURUNAN FONDASI GABUNGAN TELAPAK DAN SUMURAN (TELASUR) PADA TANAH LEMPUNG HOMOGEN
}

\author{
Neura Citra Utami ${ }^{1)}$, Niken Silmi Surjandari ${ }^{2)}$, R. Harya Dananjaya H.I. ${ }^{3)}$ \\ 1) Mahasiswa Fakultas Teknik, Prodi Teknik Sipil, Universitas Sebelas Maret \\ 2) Pengajar Fakultas Teknik, Prodi Teknik Sipil, Universitas Sebelas Maret \\ 3) Pengajar Fakultas Teknik, Prodi Teknik Sipil, Universitas Sebelas Maret \\ Jl. Ir. Sutami 36A, Surakarta 57126; Telp.0271-634524.Email: neuracitra@student.uns.ac.id
}

\begin{abstract}
An important part of a building is the foundation. Medium-level buildings as 3 to 5 floors buildings generally use deep foundations. Using the deep foundations make the cost are quite expensive, although the level of security is high. It is an alternative for middle-level buildings by combining shallow foundations and deep foundations. The combination of foot plate foundation and caisson foundation called Telasur Foundation. These alternatives are expected to be able to withstand loads for medium-sized buildings at relatively lower cost than in deep foundations. The purpose of this research is to know the value of settlement in Telasur Foundation. This research uses software based on finite element method. Telasur foundation was simulated on homogeneous clay with the variation of length divided by diameter ratio $(\mathrm{L} / d)$. The results showed that every increase of $(\mathrm{L} / d) 0,25$ ratio, able to decreased the mean value of settlement by $11,72 \%$. This research proves that Telasur foundation can withstand load better than foot plate foundation or caisson foundation, so it can be used for middle level building.
\end{abstract}

Key words: combined of footplate and caisson foundation, clay, plaxis 3D foundation, settlement.

\begin{abstract}
Abstrak
Bagian penting dari suatu gedung adalah fondasi. Bangunan tingkat menengah atau bangunan 3 hingga 5 lantai pada umumnya menggunakan fondasi dalam. Hal ini mengakibatkan biaya yang dikeluarkan cukup mahal, walaupun tingkat keamanan tinggi. Salah satu alternatif untuk bangunan tingkat menengah yaitu dengan menggabungkan fondasi dangkal dan fondasi dalam. Gabungan fondasi telapak dan fondasi sumuran disebut fondasi Telasur. Alternatif ini diharapkan mampu menahan beban untuk bangunan tingkat menengah dengan biaya yang relatif lebih murah daripada fondasi dalam. Tujuan penelitian ini untuk mengetahui besar nilai penurunan fondasi Telasur. Penelitian ini menggunakan software berbasis metode elemen hingga. Fondasi disimulasikan diatas tanah lempung homogen dengan variasi rasio panjang dan diameter sumuran $(L / d)$. Hasil penelitian menunjukkan bahwa setiap kenaikan rasio $(\mathrm{L} / \mathrm{d})$ 0,25 mengurangi nilai penurunan rata-rata sebesar $11,72 \%$. Penelitian ini membuktikan bahwa fondasi Telasur dapat menahan beban lebih baik dari fondasi telapak maupun sumuran, sehingga dapat digunakan untuk bangunan tingkat menengah.
\end{abstract}

Kata kunci: fondasi gabungan telapak dan sumuran, lepung, plaxis 3D foundation, penurunan.

\section{PENDAHULUAN}

Saat ini perkembangan konstruksi semakin cepat. Salah satu konstruksi yang paling sering dijumpai adalah konstruksi gedung. Setiap konstruksi gedung memerlukan fondasi. Fondasi merupakan bagian dari struktur bawah yang berfungsi sebagai penopang dan penyalur beban dari bangunan menuju tanah.

Fondasi terbagi menjadi dua jenis, yaitu fondasi dangkal dan fondasi dalam. Fondasi dangkal digunakan untuk bangunan 1 hingga 2 lantai atau pada lapisan tanah keras yang tidak terlalu dalam. Contoh fondasi dangkal adalah fondasi telapak, menerus, dan rakit (raft foundation). Fondasi dalam digunakan untuk bangunan tinggi atau jika lapisan tanah keras cukup dalam. Contoh fondasi dalam adalah fondasi sumuran atau kaison dan fondasi tiang.

Bangunan tingkat menengah atau bangunan 3 hingga 5 lantai biasanya menggunakan fondasi dalam. Hal ini mengakibatkan biaya yang dikeluarkan cukup mahal, walaupun tingkat keamanan tinggi. Salah satu alternatif untuk bangunan tingkat menengah yaitu dengan menggabungkan fondasi dangkal dan fondasi dalam. Alternatif ini diharapkan mampu menahan beban untuk bangunan tingkat menengah dengan biaya yang relatif lebih murah daripada fondasi dalam.

Penelitian ini menggunakan variasi rasio panjang dan diameter sumuran. Didasarkan pada rasio panjang dan diameter sumuran $(L / d)>4$ (Hardiyatmo, 2006), diharapkan penelitian ini agar lebih menggambarkan dukungan fondasi sumuran terharap fondasi gabungan telapak dan sumuran (Telasur). Analisis ini mensimulasikan model fondasi telasur pada tanah lempung homogen. Penggunaan tanah lempung homogen untuk mengetahui perilaku fondasi telasur pada kondisi tanah yang kurang baik untuk menahan beban diatasnya. Dengan adanya penelitian ini diharapkan fondasi gabungan telapak dan sumuran (Telasur) menjadi alternatif untuk bangunan tingkat menengah. Serta menjadi referensi untuk desain pembangunan fondasi telapak sumuran (telasur) dengan rasio tertentu pada tanah lempung 


\section{LANDASAN TEORI}

\section{Dasar Teori}

\section{Fondasi Telapak}

Fondasi telapak atau foot plat adalah suatu fondasi yang mendukung bangunan secara langsung pada tanah fondasi, bilamana terdapat lapisan tanah yang cukup tebal dengan kualitas yang baik dan mampu mendukung bangunan itu pada permukaan tanah atau sedikit dibawah permukaan tanah. Fondasi telapak termasuk fondasi dangkal karena perbandingan kedalaman dan lebar fondasinya $\left(D_{f} / B\right) \leq 1$ (Hardiyatmo, 2006). Fondasi telapak banyak dipakai karena efektif untuk menahan beban struktur hingga 2 lantai serta pelaksanaannya yang mudah. Besarnya tegangan kontak maksimum yang dapat ditahan oleh tanah di bawah fondasi tanpa menyebabkan keruntuhan dan penurunan yang berlebihan pada fondasi (Terzaghi dan Peck,1948) dalam Sulistyanto (2014).

\section{Fondasi Sumuran}

Fondasi kaison sering dibuat berbentuk silinder sehingga disebut fondasi sumuran. Fondasi sumuran merupakan peralihan antara fondasi dangkal dan fondasi dalam. Yang membedakan fondasi kaison dengan fondasi dangkal karena perbandingan kedalaman dan lebar fondasinya $\left(D_{f} / d\right)>4$ (Hardiyatmo, 2006). Fondasi ini banyak digunkan Karena biaya pembuatan fondasi yang relatif murah, dan tidak menggangu tanah disekitarnya. Fondasi kaison terdiri dari dua tipe, yaitu kaison bor (drilled caisson) dan kaison (caisson). Pembuatan kaison bor diawali dengan membuat lubang di alam tanah, kemudian lubang diisi dengan beton. Untuk mendapatkan kapasitas daya dukung yang tinggi, dasar kaison diperbesar menurut bentuk lonceng. Fondasi kaison berbentuk silinder beton bersamaan dengan penggalian tanah (Hardiyatmo, 2006).

\section{Penurunan}

Penurunan terbagi menjadi 3 yaitu penurunan seketika (immediate settlement), penurunan konsolidasi primer (primary consolidation settlement), dan penurunan konsolidasi sekunder (secondary consolidation settlement). Penurunan seketika (immediate settlement) terjadi dalam kondisi undrained, secara langsung ketika beban bekerja pada tanah granuler dan tanah berbutir halus kering. Penurunan konsolidasi primer (primary consolidation settlement) terjadi pada tanah berbutir halus jenuh dan memerlukan waktu, disebabkan perubahan volume tanah karena keluarnya air pori dari tanah. Penurunan konsolidasi sekunder (secondary consolidation settlement) merupakan penurunan yang terjadi setelah air pori hilang seluruhnya.

Besarnya penurunan tergantung pada karakteristik tanah dan penyebaran tekanan fondasi ke tanah di bawahnya. Pembebanan yang baik harus diberikan hingga fondasi collapse agar dapat ditentukan daya dukung ultimit neto $\left(Q_{u n}\right)$. Penurunan fondasi dapat diestimasi dari asil uji laboratorium pada contoh tanah tak terganggu. Pembebanan pada tanah pasir dan lempung memiliki periaku yang jauh berbeda, dapat dilihat pada Gambar 1.

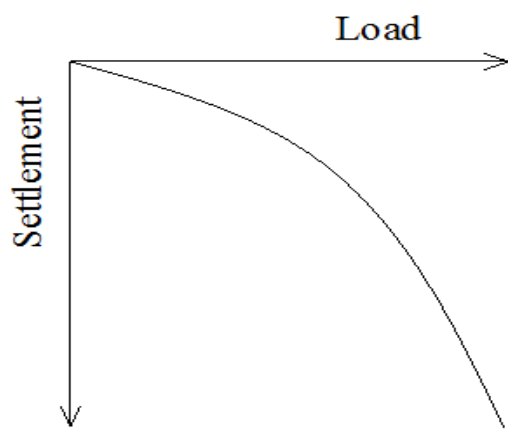

(a)

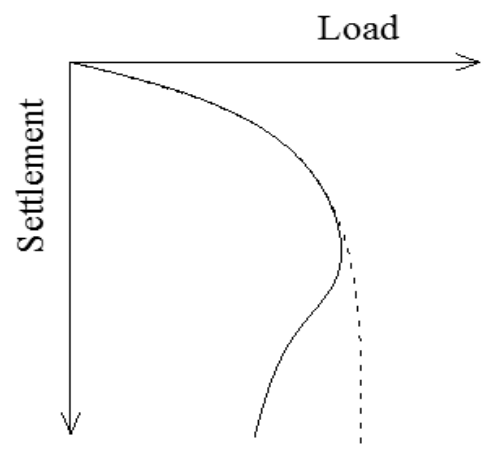

(b)

Gambar 1. Karakteristik Grafik Penurunan Terhadap Beban Pile pada (a) Tanah Pasir dan (b) Tanah Lempung (Prakash dan Sharma, 1989)

\section{METODE PENELITIAN}

Penelitian ini menggunakan data sekunder dari penelitian Budhi Sulistyanto dan Rensia Erlyana Majid (2014). Data ini digunakan sebagai data yang akan diinput dalam software metode elemen hingga meliputi parameter tanah dan parameter beton. Data tanah selengkapnya dapat dilihat pada Tabel 1. 
Tabel 1. Data Tanah (Majid dkk, 2014)

\begin{tabular}{ccc}
\hline Parameter & Nilai & Satuan \\
\hline$w$ & 18,87 & $\%$ \\
\hline$\gamma_{b}$ & 14,50 & $\mathrm{kN} / \mathrm{m}^{3}$ \\
\hline$G_{s}$ & 2,66 & - \\
\hline Gravel & 0,00 & $\%$ \\
\hline Sand & 12,3 & $\%$ \\
\hline Silt \& Clay & 87,7 & $\%$ \\
\hline$L L$ & 98,55 & $\%$ \\
\hline$P L$ & 42,39 & $\%$ \\
\hline$P I$ & 56,16 & $\mathrm{kN} / \mathrm{m}^{2}$ \\
\hline$c$ & 14,42 & $\mathrm{o}$ \\
\hline$\varphi$ & 11,53 & - \\
\hline Klasifikasi tanah & $C H$ (lempung anorganik & plastisitas tinggi) \\
\hline
\end{tabular}

Data sekunder yang didapatkan, diolah terlebih dahulu agar satuan yang digunakan sesuai dengan yang terdapat dalam program. Data tanah yang digunakan sebagai input ke dalam program berbasis metode elemen hingga, yang ditampilkan dalam Tabel 2. Parameter lain yang dibutuhkan untuk input kedalam program adalah material beton untuk fondasi telapak dan sumuran ditampilkan pada Tabel 3.

Tabel 2. Parameter Input untuk Material Tanah Dasar (Majid dkk, 2014)

\begin{tabular}{lcc}
\multicolumn{1}{c}{ Parameter } & Nilai & Sumber \\
\hline Model Material & Mohr-Coulomb & - \\
\hline Perilaku Material & Undrained & - \\
\hline Berat Isi Tanah Tidak Jenuh $\left(\gamma_{\text {unsat }}\right)$ & $14,50 \mathrm{kN} / \mathrm{m}^{3}$ & Data Sekunder \\
\hline Berat Isi Tanah Jenuh $\left(\gamma_{\text {sat }}\right)$ & $19,81 \mathrm{kN} / \mathrm{m}^{3}$ & Perhitungan \\
\hline Modulus Young $(E)$ & $6000 \mathrm{kN} / \mathrm{m}^{2}$ & Korelasi Empiris \\
\hline Angka Poisson $(v)$ & 0,15 & Korelasi Empiris \\
\hline Kohesi $(c)$ & $14,42 \mathrm{kN} / \mathrm{m}^{2}$ & Data Sekunder \\
\hline Sudut Gesek Dalam $(\varphi)$ & $11,53^{\circ}$ & Data Sekunder \\
\hline Sudut Dilatansi $(\psi)$ & $0^{\circ}$ & Tutorial Plaxis \\
\hline Faktor Reduksi Interface $\left(\mathrm{R}_{\text {inter }}\right)$ & 1 & Tutorial Plaxis \\
\hline
\end{tabular}

Tabel 3. Parameter Input Material Fondasi (Majid dkk, 2014)

\begin{tabular}{lcc}
\multicolumn{1}{c}{ Parameter } & Telapak & Sumuran \\
\hline Perilaku material & Isotropic & Isotropic \\
\hline Tebal $(d)$ & $0,2 \mathrm{~m}$ & $0,2 \mathrm{~m}$ \\
\hline Berat jenis $(\gamma)$ & $24 \mathrm{kN} / \mathrm{m}^{3}$ & $24 \mathrm{kN} / \mathrm{m}^{3}$ \\
\hline Modulus Elastisitas $(E)$ & $2,35 \times 10^{7} \mathrm{kN} / \mathrm{m}^{2}$ & $2,35 \times 10^{7} \mathrm{kN} / \mathrm{m}^{2}$ \\
\hline Angka Poisson $(v)$ & 0,2 & 0,2 \\
\hline Diameter & - & $1 \mathrm{~m}$ \\
\hline
\end{tabular}

Dari table diatas, dapat diambil nlai-nilai yang akan digunakan sebagai input software. Contohnya nilai Modulus Young sebesar $6000 \mathrm{kN} / \mathrm{m}^{2}$ yang tertera padaTable 2, begitupun data lainnya. 
Penelitian ini diawali dengan menentukan beban yang akan diaplikasikan pada model fondasi dan rasio yang telah ditetapkan pada Tabel 4. Beban rencana fondasi sebesar $1000 \mathrm{kN}$ disesuaikan dengan beban fondasi untuk bangunan tingkat menengah atau 3 sampai 5 lantai. Sesuai dengan ASTM D 1143 - 81 dimana pemberian beban sampai dengan $200 \%$ beban rencana, sehingga beban yang diaplikasikan adalah dari $0 \mathrm{kN}$ hingga $2000 \mathrm{kN}$ dengan rentang beban $100 \mathrm{kN}$. Pemodelan fondasi gabungan yang digunakan dapat dilihat pada Gambar 2.

Tabel 4. Model Fondasi Gabungan dalam Penelitian

\begin{tabular}{ccccccc}
\hline \multirow{2}{*}{ No. } & \multirow{2}{*}{ Tipe Fondasi } & \multirow{2}{*}{ Rasio $(L / d)$} & \multicolumn{2}{c}{ Fondasi Telapak } & \multicolumn{2}{c}{ Fondasi Sumuran } \\
\cline { 3 - 7 } & & - & $1,5 \times 1,5$ & 1,5 & $D(\mathrm{~m})$ & $L(\mathrm{~m})$ \\
\hline 1. & Telapak & - & - & - & 1 & - \\
\hline 2. & Sumuran & - & $1,5 \times 1,5$ & 1,5 & 1 & 4,25 \\
\hline 3. & Telasur 1 & 4,25 & $1,5 \times 1,5$ & 1,5 & 1 & 4,25 \\
\hline 4. & Telasur 2 & 4,50 & $1,5 \times 1,5$ & 1,5 & 1 & 4,75 \\
\hline 5. & Telasur 3 & 4,75 & $1,5 \times 1,5$ & 1,5 & 1 & 5,00 \\
\hline 6. & Telasur 4 & 5,00 & $1,5 \times 1,5$ & 1,5 & 1 & 5,25 \\
\hline 7. & Telasur 5 & 5,25 & $1,5 \times 1,5$ & 1,5 & 1 & 5,50 \\
\hline 8. & Telasur 6 & 5,50 & $1,5 \times 1,5$ & 1,5 & 1 & 5,75 \\
\hline 9. & Telasur 7 & 5,75 & $1,5 \times 1,5$ & 1,5 & 1 & 6,00 \\
\hline 10. & Telasur 8 & 6,00 & & & &
\end{tabular}

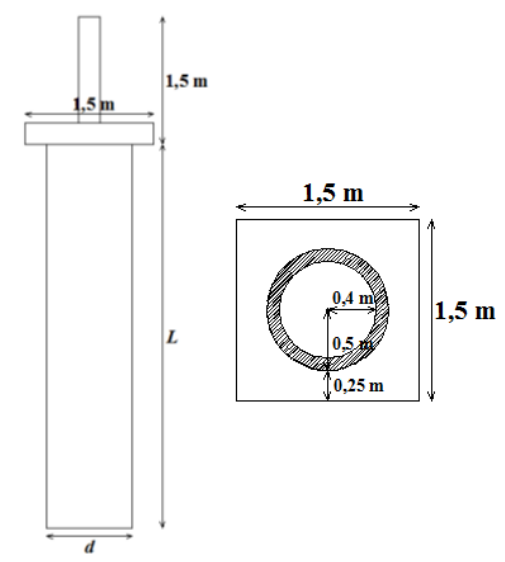

Gambar 2. Tampak Model Fondasi Gabungan

\section{HASIL DAN PEMBAHASAN}

\section{Penurunan}

Analisis penurunan fondasi dilakukan untuk mengetahui karakteristik grafik penurunan fondasi gabungan terhadap beban. Rekapitulasi penurunan fondasi terhadap beban ditampilkan pada Tabel 5.

Tabel 5. Rekapitulasi Hasil Penurunan Fondasi Telasur

\begin{tabular}{|c|c|c|c|c|c|c|c|c|c|c|}
\hline \multirow{2}{*}{$\begin{array}{c}\text { Beban } \\
(\mathrm{kN})\end{array}$} & \multicolumn{10}{|c|}{ Penurunan $(\mathrm{mm})$} \\
\hline & Telapak & Sumuran & $\begin{array}{c}\text { Telasur } \\
1\end{array}$ & $\begin{array}{c}\text { Telasur } \\
2\end{array}$ & $\begin{array}{c}\text { Telasur } \\
3\end{array}$ & $\begin{array}{c}\text { Telasur } \\
4\end{array}$ & $\begin{array}{c}\text { Telasur } \\
5\end{array}$ & $\begin{array}{c}\text { Telasur } \\
6\end{array}$ & $\begin{array}{c}\text { Telasur } \\
7\end{array}$ & $\begin{array}{c}\text { Telasur } \\
8\end{array}$ \\
\hline 0 & 0,252 & 0,548 & 0,215 & 0,389 & 0,132 & 0,348 & 0,057 & 0,111 & 0,149 & 0,356 \\
\hline 100 & 2,238 & 1,573 & 1,501 & 1,461 & 1,424 & 1,403 & 1,37 & 1,338 & 1,307 & 1,279 \\
\hline 200 & 4,052 & 3,176 & 3,006 & 2,926 & 2,848 & 2,459 & 2,739 & 2,675 & 2,615 & 2,558 \\
\hline 300 & 6,458 & 4,795 & 4,532 & 4,41 & 4,287 & 3,877 & 4,124 & 4,023 & 3,929 & 3,842 \\
\hline 400 & 9,608 & 6,444 & 6,075 & 5,909 & 5,745 & 5,313 & 5,524 & 5,387 & 5,261 & 5,142 \\
\hline 500 & 13,703 & 8,42 & 7,664 & 7,428 & 7,217 & 6,76 & 6,932 & 6,758 & 6,599 & 6,45 \\
\hline 600 & 18,918 & 11,526 & 9,35 & 9,014 & 8,748 & 8,254 & 8,377 & 8,146 & 7,945 & 7,761 \\
\hline 700 & 25,469 & 17,616 & 11,292 & 10,778 & 10,425 & 9,841 & 9,886 & 9,596 & 9,329 & 9,089 \\
\hline 800 & 33,537 & - & 13,958 & 13,094 & 12,409 & 11,57 & 11,52 & 11,191 & 10,819 & 10,52 \\
\hline 900 & 45,048 & - & 17,706 & 16,314 & 15,292 & 14,23 & 13,924 & 13,349 & 12,573 & 12,2 \\
\hline 1000 & 61,003 & - & 23,585 & 20,722 & 19,067 & 18,043 & 17,13 & 16,047 & 15,189 & 14,299 \\
\hline 1100 & 81,787 & - & 34,348 & 28,718 & 25,13 & 23,431 & 21,627 & 19,916 & 18,633 & 17,394 \\
\hline 1200 & - & - & 51,595 & 42,571 & 36,202 & 33,569 & 29,287 & 25,934 & 23,332 & 21,44 \\
\hline
\end{tabular}


Lanjutan Tabel 5. Rekapitulasi Hasil Penurunan Fondasi Telasur

\begin{tabular}{|c|c|c|c|c|c|c|c|c|c|c|}
\hline \multirow{2}{*}{$\begin{array}{c}\text { Beban } \\
(\mathrm{kN})\end{array}$} & \multicolumn{10}{|c|}{ Penurunan (mm) } \\
\hline & Telapak & Sumuran & $\begin{array}{c}\text { Telasur } \\
1\end{array}$ & $\begin{array}{c}\text { Telasur } \\
2\end{array}$ & $\begin{array}{c}\text { Telasur } \\
3\end{array}$ & $\begin{array}{c}\text { Telasur } \\
4\end{array}$ & $\begin{array}{c}\text { Telasur } \\
5\end{array}$ & $\begin{array}{c}\text { Telasur } \\
6\end{array}$ & $\begin{array}{c}\text { Telasur } \\
7\end{array}$ & $\begin{array}{c}\text { Telasur } \\
8\end{array}$ \\
\hline 1300 & - & - & - & 63,836 & 53,648 & 49,426 & 43,074 & 36,862 & 31,768 & 27,7 \\
\hline 1400 & - & - & - & - & - & 74,513 & 64,149 & 52,98 & 45,779 & 39,3 \\
\hline 1500 & - & - & - & - & - & - & 96,261 & 78,496 & 66,773 & 56,018 \\
\hline 1600 & - & - & - & - & - & - & - & - & 100,433 & 83,02 \\
\hline 1700 & - & - & - & - & - & - & - & - & - & - \\
\hline 1800 & - & - & - & - & - & - & - & - & - & - \\
\hline 1900 & - & - & - & - & - & - & - & - & - & - \\
\hline 2000 & - & - & - & - & - & - & - & - & - & - \\
\hline
\end{tabular}

Gambar 3. merupakan grafik penurunan terhadap beban dari fondasi telapak, sumuran dan fondasi gabungan telapak sumuran (Telasur 1). Telasur 1 ini dimodelkan memiliki diameter sumuran $1 \mathrm{~m}$ dan panjang sumuran 4,25 m. Data Tabel 5 dan grafik Gambar 3 dapat diketahui bahwa penurunan untuk beban $700 \mathrm{kN}$ pada fondasi telapak sebesar 25,469 mm atau 0,025469 m, fondasi sumuran sebesar 17,616 mm, dan Telasur 1 sebesar 11,292 $\mathrm{mm}$ atau $0,011292 \mathrm{~m}$. Hal ini membuktikan bahwa fondasi gabungan memberikan pengurangan nilai penurunan yang cukup besar.

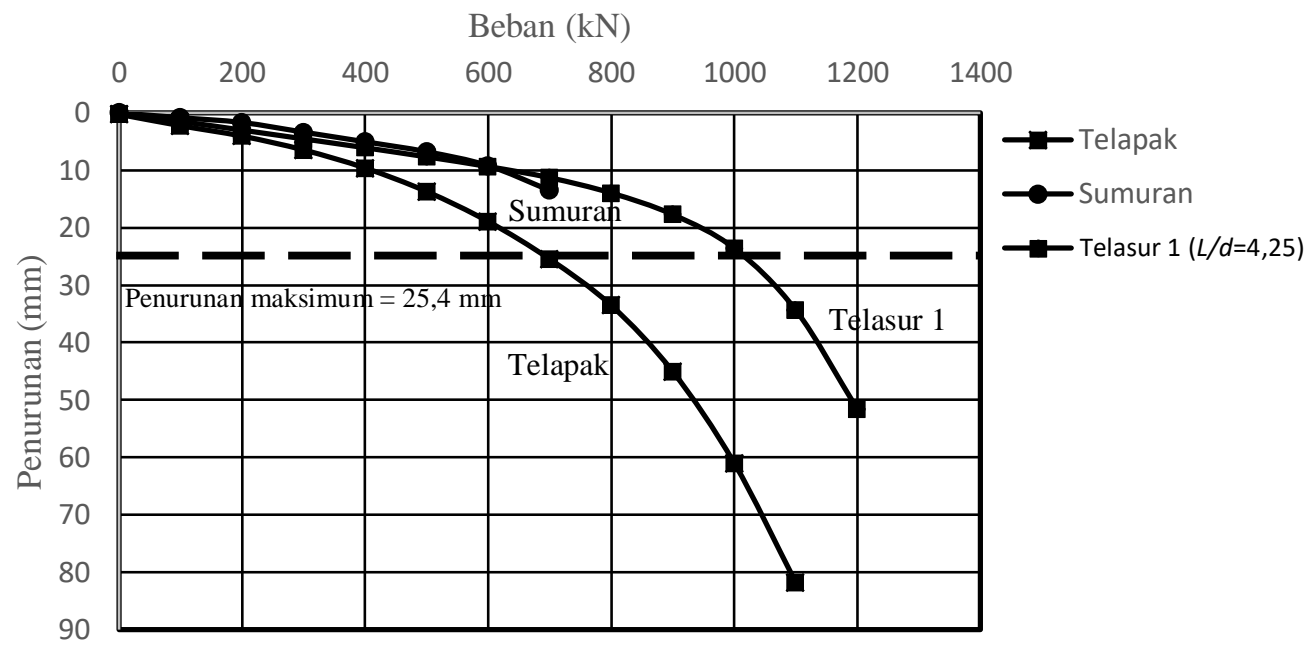

Gambar 3. Grafik Penurunan fondasi telapak, sumuran, dan Telasur 1

Gambar 3. merupakan grafik penurunan terhadap beban dari fondasi telapak, sumuran dan fondasi gabungan telapak sumuran (Telasur 1). Telasur 1 ini dimodelkan memiliki diameter sumuran $1 \mathrm{~m}$ dan panjang sumuran 4,25 m. Data Tabel 4.1 dan grafik Gambar 4.1 dapat diketahui bahwa penurunan untuk beban $700 \mathrm{kN}$ pada fondasi telapak sebesar 25,469 $\mathrm{mm}$ atau $0,025469 \mathrm{~m}$, fondasi sumuran sebesar $17,616 \mathrm{~mm}$, dan Telasur 1 sebesar 11,292 $\mathrm{mm}$ atau $0,011292 \mathrm{~m}$. Hal ini membuktikan bahwa fondasi gabungan memberikan pengurangan nilai penurunan yang cukup besar. 


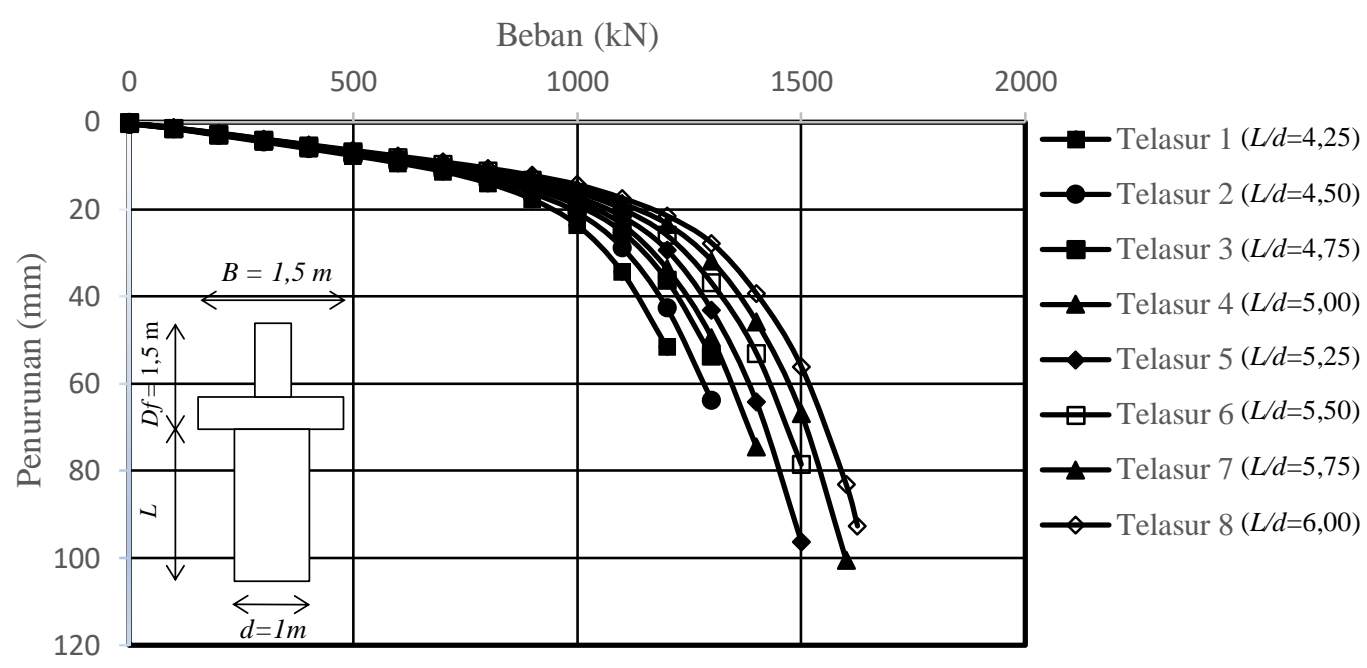

Gambar 4. Grafik Hasil Penurunan Fondasi Telasur

Gambar 3. dan 4. menunjukkan karakteristik yang sama dengan grafik penurunan terhadap beban pada tanah lempung pada Gambar 1. Hal ini terlihat jelas pada grafik penurunan fondasi telapak, sumuran, maupun fondasi gabungan, sebab tanah sekitar fondasi sudah mengalami collapse sebelum pemberian beban sampai $200 \%$ dari beban rencana. Secara keseluruhan, hasil penurunan dari model fondasi telasur lebih kecil dibandingkan dengan penurunan pada fondasi telapak maupun sumuran saja. Pada beban yang sama yaitu $700 \mathrm{kN}$, fondasi Telasur 1 mengalami penurunan sebesar $11,292 \mathrm{~mm}$ atau turun $55,663 \%$ dari penurunan fondasi telapak dan 35,899\% dari fondasi sumuran. Rasio antara panjang dan diameter fondasi sumuran $(L / d)$ ikut mempengaruhi besarnya penurunan yang terjadi. Pada Gambar 4. dapat diketahui semakin panjang fondai sumuran, maka penurunan yang terjadi semakin kecil. Penggabungan fondasi telapak dan sumuran (Telasur) dapat mengurangi besarnya penurunan tanah yang terjadi. Fondasi Telasur dengan variasi rasio panjang dan diameter sumuran $(L / d)$, rata-rata penurunan setiap kenaikan 0,25 berkurang sebesar 11,7243\%.

\section{SIMPULAN}

Perilaku grafik penurunan terhadap beban untuk fondasi telapak, sumuran dan Telasur menunjukkan perilaku yang sama, yang berbeda hanyalah besar nilai penurunannya. Model fondasi gabungan Telasur membuat besar nilai penurunan fondasi menjadi lebih kecil. Rasio $(L / d)$ dengan variabel bebas $L$ dan vaiabel tetap $d$, memberikan pengaruh dalam penurunan. Semakin besar rasio $(L / d)$ penurunan yang terjadi semakin kecil,. Setiap kenaikan rasio (L/d) 0,25 mengurangi nilai penurunan rata-rata sebesar $11,72 \%$.

\section{REKOMENDASI}

1. Penelitian ini dapat dikembangkan lagi dengan memodelkan fondasi gabungan telapak dan sumuran pada tanah berlapis lebih dari 2 lapis.

2. Memodelkan fondasi gabungan telapak dan sumuran dengan mempertimbangkan pengaruh muka air tanah.

3. Memodelkan fondasi gabungan telapak dan sumuran dengan variasi tebal telapak atau ketebalan sumuran.

4. Pemodelan pembebanan dengan cara cyclic loading seperti pengujian pembebanan yang dilakukan di lapangan.

\section{UCAPAN TERIMAKASIH}

Ucapan terima kasih pertama ditujukan kepada Allah SWT atas limpahan rahmat dan nikmatnya. Selanjutnya kepada Dr. Niken Silmi Surjandari, S.T., M.T. dan R. Harya Dananjaya H.I., S.T., M.Eng. selaku dosen pembimbing yang telah memberi arahan dan masukan dalam penelitian ini.

\section{REFERENSI}

Afandi, Heri, 2015. Simulasi Perilaku Pondasi Gabungan Telapak dan Sumuran pada Tanah Pasir Homogen dengan Variasi Kedalaman Telapak dan Panjang Sumuran. Surakarta : Universitas Sebelas Maret.

Bowles, Joseph E., 1968. Foundation Analysis and Design. Indianapolis: McGraw-Hill Book Company.

Briaud, Prof. Jean-Louis dkk., 2013. ISSMGE Combined Pile-Raft Fundation Guideline. Germany : Technische Universitat Darmstadt. 
Brinkgreve, R.B.J., W. Broere. 2004. Plaxis 3D Foundation Tutorial Manual version 1. Netherlands: Delf University of Technology \& PLAXIS bv.

Hardyatmo, Hary Christady, 2006. Teknik Pondasi 1.Yogyakarta : Beta Offset.

Hardyatmo, Hary Christady, 2008. Teknik Pondasi 2. Yogyakarta : Beta Offset.

Hardyatmo, Hary Christady, 2010. Mekanika Tanah 1. Yogyakarta : Gajah Mada University Press.

Majid, Rensia Erlyana, 2014. Simulasi Perilaku Pondasi Gabungan Foot Plat dan Sumuran Dengan Variasi Kedalaman Foot Plat dan Panjang Sumuran. Surakarta : Universitas Sebelas Maret.

Prakash, Shamsher, Hari D. Sharma, 1990. Pile Foundation in Engineering Practice. New York : Wiley Intersection Publication.

Purnomo, Ari, 2015. Simulasi Perilaku Pondasi Gabungan Telapak dan Sumuran dengan Variasi Kedalaman Telapak pada Tanah Lempung Berlapis. Surakarta : Universitas Sebelas Maret.

Sulistyanto, Budi, 2014. Simulasi Perilaku Pondasi Gabungan Foot Plat dan Sumuran Dengan Variasi Dimensi Foot Plat dan Diameter Sumuran. Surakarta : Universitas Sebelas Maret.

Suhaemi, Muhammad, 2015. Simulasi Perilaku Pondasi Gabungan Telapak dan Sumuran pada Tanah Pasir Homogen dengan Variasi Dmensi Telapak dan Diameter Sumuran. Surakarta : Universitas Sebelas Maret.

Terzaghi, Karl, Ralph B. Peck, 1967. Soil Mechanics in Engineering Practice. New York : Wiley - Interscience.

Waskito, Habib Abduljabar, 2015. Simulasi Perilaku Pondasi Gabungan Telapak dan Sumuran dengan Variasi Dmensi Telapak dan Diameter Sumuran pada Tanah Lempung Berlapis. Surakarta : Universitas Sebelas Maret. 